\title{
SERS-Based Immunoassay Enhanced with Silver Probe for Selective Separation and Detection of Alzheimer's Disease Biomarkers
}

This article was published in the following Dove Press journal: International Journal of Nanomedicine

\author{
Dan $Y u^{1,2, *}$ \\ Qilong Yin (D) $1,3, *$ \\ Jiwei Wang ${ }^{1} *$ \\ Jian Yang' \\ Zimeng Chen' \\ Zihan Gao' \\ Qingli Huang ${ }^{1,4}$ \\ Shibao $\mathrm{Li}^{1,3}$
}

\begin{abstract}
'Medical Technology School of Xuzhou Medical University, Xuzhou, Jiangsu, 221000, People's Republic of China; 2 Jiangsu Key Laboratory of Medical Science and Laboratory Medicine, School of Medicine, Jiangsu University, Zhenjiang, Jiangsu, 212013, People's Republic of China; ${ }^{3}$ Department of Laboratory Medicine, Affiliated Hospital of Xuzhou Medical University, Xuzhou, Jiangsu, 221000, People's Republic of China; ${ }^{4}$ Public Experimental Research of Xuzhou Medical University, Xuzhou, Jiangsu,

221000, People's Republic of China

*These authors contributed equally to this work
\end{abstract}

Correspondence: Qingli Huang Public Experimental Research of Xuzhou Medical University, Xuzhou, Jiangsu, 221000 , People's Republic of China

$\mathrm{Tel}+86$ I5I50043097

Fax +86516 8326209l

Email qlhuang@xzhmu.edu.cn

Shibao Li

Department of Laboratory Medicine, Affiliated Hospital of Xuzhou Medical

University, Xuzhou, Jiangsu, 221000,

People's Republic of China

Tel +86 I58952I 2960

Fax +865168335365 I

Email sdjnshlb@xzhmu.edu.cn
Purpose: Developing a sensitive SERS-based method to quantitatively detect serum biomarkers (A $31-42$ and P-Tau-181) for the early diagnosis of Alzheimer's disease (AD).

Methods: In this study, a novel SERS-based sandwich immunoassay, which consists of tannin-capped silver nanoparticles and magnetic graphene oxide $\left(\mathrm{Fe}_{3} \mathrm{O}_{4} @ \mathrm{GOs}\right)$, was developed. We firstly applied this method for the detection of protein standards in buffer solution, obtaining the regression equation. Then, its potential value on real serum samples of AD was further explored.

Results: The detection linear range of $\mathrm{A} \beta 1-42$ and $\mathrm{P}-\mathrm{Tau}-181$ protein standards were observed to range from $100 \mathrm{pg} \mathrm{mL}^{-1}$ to $10 \mathrm{fg} \mathrm{mL}^{-1}, 100 \mathrm{pg} \mathrm{mL}^{-1}$ to $1 \mathrm{fg} \mathrm{mL}^{-1}$ respectively. We finally explored clinical application of the proposed method in 63 serum samples. As a result, P-tau-181 differentiated $\mathrm{AD}$ from non-AD dementia patients $(\mathrm{AUC}=0.770)$, with a more favored ROC than A $\beta 1-42$ (AUC $=0.383$ ).

Conclusion: The developed SERS-based immunoassay is successfully applied to the determination of A $\beta 1-42$ and P-Tau-181 in human serum specimens, which provides a promising tool for the early diagnosis of AD.

Keywords: surface-enhanced Raman scattering, silver probe, Alzheimer's disease, biomarker, diagnosis

\section{Introduction}

Alzheimer's disease (AD) is a serious neurodegenerative disease of the cerebral nervous system, which performs a high morbidity in the elderly. ${ }^{1}$ Deaths of Alzheimer's disease resulted in increase of $71 \%$ in 14 years. By 2050, practically one million new cases are expected to occur each year, which means the occurrence of a new case every 33 seconds. ${ }^{2}$ With the progression of $\mathrm{AD}$, patients can suffer from severe cognitive decline and memory impairment, finally leading to dementia and frailty. ${ }^{3-5}$ Since there is no cure currently, early diagnosis is rather critical for the treatment.

Previous studies have confirmed two neuropathological symbols of AD patients, amyloid $\beta$ peptide $(A \beta)$ and hyperphosphorylated Tau protein. ${ }^{6,7}$ Among all subtypes of amyloid, $A \beta 1-42$ shows more amyloidogenicity and toxicity. ${ }^{8}$ In addition, it has been discovered that Tau proteins in the brain of $\mathrm{AD}$ patients exist in phosphorylated form and combine with each other in neurocytes, constituting the so-called NFT. ${ }^{9}$ Therefore, A $\beta 1-42$ and P-Tau-181 have been widely used as 
biomarkers for $\mathrm{AD}$ diagnosis. At present, the concentration of $A \beta$-amyloid and Tau protein was mainly detected by enzyme-linked immunosorbent assay (ELISA). In addition, biosensors or magnetic contrast agents based on nanomaterials have shown many advantages for the early diagnosis of AD. It is indicated that nanoparticles could be used as drug delivery tools for the treatment of neurological diseases. ${ }^{10-12}$ However, the detection limit of ELISA is only $0.312 \mathrm{ng} \mathrm{mL}^{-1}(\mathrm{~A} \beta)$ and $0.15 \mathrm{ng} \mathrm{mL}^{-1}$ (Tau), which prevents its clinical application. Therefore, the development of an ultra-sensitive detection technology for $A \beta$ amyloid and Tau protein is urgently needed for the early diagnosis of AD.

Surface-enhanced Raman scattering (SERS), a novel analytical technique, has the superiority of enhancing Raman signals up to $10^{4}-10^{7}$ magnitude compared to traditional Raman spectroscopy. ${ }^{13}$ Furthermore, SERS can be rather more sensitive compared to other methods, such as ELISA, especially when the sample contains a very small amount of test substances. ${ }^{13-16}$ Due to the above advantages, SERS has been widely applied for qualitative and quantitative detection of chemical harmful substance and biological detection. ${ }^{13,17-19}$ Tannic acid (TA) can adhere to a variety of different materials and form multifunctional surface coatings for technical and biological applications. Weber et al suggested that TA could form a continuous coating in the aqueous buffer system in the presence of four-coordinate or higher metalloid anions. ${ }^{20}$ This makes it widely used for material wrapping and coating modification.

Ag or Au-enhanced Raman spectroscopy has been widely used for SERS-based biological detection. ${ }^{21,22}$ Due to good magnetic properties, $\mathrm{Fe}_{3} \mathrm{O}_{4}$ magnetic nanoparticles have been widely used in biological detection and analysis. ${ }^{23,24}$ However, $\mathrm{Fe}_{3} \mathrm{O}_{4}$ is intended to be highly gathered because of the interaction of magnetic dipoles. Poor performance, such as narrow linear range and low sensitivity, are drawbacks of biological sensors constructed with pure $\mathrm{Fe}_{3} \mathrm{O}_{4}$ nanoparticles. ${ }^{25,26}$ To solve this problem, graphene sheets decorated with magnetic nanoparticles are a good choice. Graphene oxide usually functions as a biosensor, which has the superiority of low cost, good biocompatibility and superb dispersion. ${ }^{27,28}$ Graphene sheets decorated with magnetic nanoparticles have been proved a superior performance in biomedical fields, which could not be realized by either pure GO or pure $\mathrm{Fe}_{3} \mathrm{O}_{4} \cdot{ }^{25,26}$
In this paper, a SERS-based sandwich immunoassay was developed and applied for the early diagnosis of Alzheimer's disease. On one hand, uniform tannincapped Ag nanoparticles were chosen to be a probe for SERS detection, which were labeled with 4-mercaptobenzoic acid (4-MBA). On the other hand, magnetic graphene oxide $\left(\mathrm{Fe}_{3} \mathrm{O}_{4} @ \mathrm{GOs}\right)$ was used as the magnetic SERS substrate, which not only can enhance Raman signal but also have good dispersibility. Then, this SERS-based immunoassay was applied on both protein standards and real serum samples. The results demonstrated that this method could accurately and sensitively detect A $\beta 1-42$ and P-Tau-181 in human serum samples, which provided a promising tool for early diagnosis of Alzheimer's disease.

\section{Materials and Methods}

Materials and Instruments

Silver nitrate $\left(\mathrm{AgNO}_{3}\right)$, chlorauric acid $\left(\mathrm{HAuCl}_{4}\right)$, trisodium citrate, tannic acid, hydrogen peroxide $\left(\mathrm{H}_{2} \mathrm{O}_{2}\right)$, hydrazine hydrate $\left(\mathrm{N}_{2} \mathrm{H}_{4} \cdot \mathrm{H}_{2} \mathrm{O}\right)$, 4-mercaptobenzoic acid (4-MBA), N-hydroxythiosuccinimide (NHS), 1-(3-dimethylaminopropyl)-3-ethylcarbodiimide hydrochloride (EDC), A $\beta$-amyloid (1-42), P-Tau (181) protein, phosphate buffer saline (PBS) buffer, bovine serum albumin (BSA), magnetic graphene oxide dispersion $\left(\mathrm{Fe}_{3} \mathrm{O}_{4}\right.$ @GOs, Jiangsu Xianfeng Nano Material Technology Co., Ltd.). ELISA kit, anti-A $\beta$-amyloid antibody and anti-tau antibody were purchased from Shenzhen Anqun Biological Engineering Co., Ltd.

The morphologies of the as-prepared samples were detected on a Tecnai T12 transmission electron microscopy (TEM) and scanning electron microscopy (SEM) (FEI, America). UV-vis spectra were acquired on a UVvis spectrometer (AOE, Shanghai). The Raman and SERS spectra were obtained on Renishaw inVia Raman spectrometer using $532 \mathrm{~nm}$ laser at room temperature in the range of 400-2000 $\mathrm{cm}^{-1}$. Spectra were accumulated 1 scan with an exposure time of $10 \mathrm{~s}$. The beam diameter was approximately $1 \mathrm{~mm}$ on the sample surface. The reaction solutions were thoroughly stirred on a Heating magnetic stirrer (IKA, Germany).

\section{Methods}

The sample for SEM was prepared by adding $20 \mu \mathrm{L} \mathrm{Fe}_{3} \mathrm{O}_{4}$ @ GOs solution on tin foil and was observed by SEM after drying, while the sample for TEM was prepared by adding 
$10 \mu \mathrm{L}$ synthesized solution on copper grids successively coated with thin films of carbon. All the procedures were conducted on filter paper.

\section{Serum Samples}

Serum samples were collected from the Department of Clinical Laboratory of Xuzhou Medical University Affiliated Hospital. Clinical pathological information (gender, age, disease diagnosis) was obtained from medical records. All the serum samples and clinical information were conducted in accordance with the Declaration of Helsinki. All serum samples were approved by the Ethics Committee of the Affiliated Hospital of Xuzhou Medical University (XYFY2016-JS004-01), and all subjects signed the informed consent.

\section{Preparation of Immune Probes}

We have applied different metal materials as immunoprobes to make a comparison. The synthesis methods were as follows:

Tannin-capped Ag probe: $0.17 \mathrm{~g}$ silver nitrate was dissolved in $100 \mathrm{~mL}$ deionized water, stirring on a magnetic stirrer. After that, $0.05 \mathrm{~g}$ tannic acid was added and kept stirring for some seconds. Next, $1.2 \mathrm{~mL}$ $\mathrm{H}_{2} \mathrm{O}_{2}$ and $1.2 \mathrm{~mL} \mathrm{~N} \mathrm{~N}_{2} \mathrm{H}_{4} \cdot \mathrm{H}_{2} \mathrm{O}$ was added to the solution and the mixture was continued to react for $20 \mathrm{~min}$ under vigorous stirring. The prepared solution was stored at $4{ }^{\circ} \mathrm{C}$ in the dark.

Au probe: To develop a nano-gold probe,$^{29,30} 100 \mathrm{~mL}$ $\mathrm{HAuCl}_{4}\left(0.1 \mathrm{mg} \mathrm{mL} \mathrm{mL}^{-1}\right)$ was heated to boiling using a constant temperature magnetic stirrer. Next, $4 \mathrm{~mL}$ of sodium citrate solution $\left(0.01 \mathrm{~g} \mathrm{~mL}^{-1}\right)$ was immediately added to the boiling solution with vigorous stirring. The mixture was then heated for a further 10 minutes until the reaction solution turned wine red. Finally, stop heating and continue stirring for 15 minutes. The prepared solution was allowed to cool to room temperature and refrigerated at $4^{\circ} \mathrm{C}$ for later use.

$\mathrm{Au} @$ Ag probe: We synthesized the gold-silver alloy nanoprobe by hydrothermal method. At first, $16 \mathrm{~mL}$ deionized water, $3 \mathrm{~mL}$ of absolute ethanol, and $0.5 \mathrm{~mL}$ of (3-aminopropyl) triethoxysilane (APS) were mixed together in an autoclave and kept stirring for $30 \mathrm{~min}$. Next, $3 \mathrm{~mL} \mathrm{HAuCl}_{4}\left(10 \mathrm{mg} \mathrm{mL}^{-1}\right)$ was dropped into the autoclave. After stirring for $5 \mathrm{~min}, 10 \mathrm{mg} \mathrm{AgNO}_{3}$ was added into the reaction solution and stirred for another 5 min. Finally, the solution was reacted at $100^{\circ} \mathrm{C}$ for 6 hours. The prepared nanoparticles were collected by centrifugation. After the supernatant had been removed, the particles were dispersed again in deionized water for further use.

Synthesis of 4-MBA labeled probes: In order to obtain 4-MBA-labeled nanoprobes, first, $4 \mathrm{~mL}$ as-prepared $\mathrm{Ag}$ (or $\mathrm{Au}$ or $\mathrm{Ag} @ \mathrm{Ag}$ ) probe solutions $\left(3.25 \mathrm{mg} \mathrm{mL}^{-1}\right.$ ) was washed by centrifugation at $14,000 \mathrm{rpm}$ for $20 \mathrm{~min}$ and redispersed into $1 \mathrm{~mL}$ of deionized water. Next, $200 \mu \mathrm{L}$ of 4-MBA ethanol solution ( $1 \mathrm{mM})$ was added to the solution under vigorous stirring for $7 \mathrm{~h}$. Then, washing twice with water to remove unbound 4-MBA molecules, and the sediment of the 4MBA-labelled probe was dissolved in $1 \mathrm{~mL}$ PBS solution finally.

Developing antibody-attached immune probes: First, $50 \mu \mathrm{L} \mathrm{EDC}(100 \mathrm{mM})$ and $80 \mu \mathrm{L}$ NHS $(100 \mathrm{mM})$ was added to the 4-MBA-labeled probe dispersion, and then stirred at room temperature for $30 \mathrm{~min}$. Secondly, the solution was washed twice with $0.01 \mathrm{~mol} \mathrm{~L}^{-1} \mathrm{PBS}$, and redispersed in $1 \mathrm{~mL}$ PBS. After that, $200 \mu \mathrm{L} 100 \mu \mathrm{g} \mathrm{mL}^{-1}$ anti-A $\beta$-amyloid antibody (or anti-tau antibody) was added to the dispersion and incubated at $4^{\circ} \mathrm{C}$ for $12 \mathrm{~h}$. To avoid the unspecific absorption of antigens, $100 \mu \mathrm{L} \mathrm{3 \%} \mathrm{BSA} \mathrm{was}$ added to the above mixed solution as a blocking solution. The mixture was left at $4^{\circ} \mathrm{C}$ for $6 \mathrm{~h}$ and dispersed in $1 \mathrm{~mL}$ PBS after being centrifuged.

\section{Preparation of Immune $\mathrm{Fe}_{3} \mathrm{O}_{4} @ \mathrm{GO}$ Substrate}

In order to obtain an antibody-conjugated immune substrate, we have utilized the covalent conjugate between $\mathrm{COOH}$ of graphene oxide and $-\mathrm{NH}_{2}$ of antibodies. $100 \mu \mathrm{L}$ $5 \mathrm{mg} \mathrm{mL} \mathrm{m}^{-1}$ magnetic graphene oxide dispersion was dispersed in $1 \mathrm{~mL}$ of PBS solution. Next, $200 \mu \mathrm{L} 100$ $\mu \mathrm{g} \mathrm{mL}^{-1}$ anti-A $\beta$-amyloid antibody (or anti-tau antibody) was added to the solution and then for ultrasonic dispersion. The solution was incubated at $4^{\circ} \mathrm{C}$ for more than 12 h. Then, $50 \mu \mathrm{L} 3 \% \mathrm{BSA}$ was added into the mixture and was left at $4^{\circ} \mathrm{C}$ for $6 \mathrm{~h}$. Finally, the immune $\mathrm{Fe}_{3} \mathrm{O}_{4} @ \mathrm{GO}$ substrate was collected through magnetic separation and re-suspended in $1 \mathrm{~mL}$ PBS.

\section{Developing Sandwich Immunoassays for SERS Measurements}

As shown in Scheme 1, the immunoassays were conducted by a typical sandwich-type structure. Firstly, $150 \mu \mathrm{L}$ asprepared SERS substrate was dropped into a $2 \mathrm{~mL}$ EP tube and then $40 \mu \mathrm{L}$ of $\mathrm{A} \beta-142$ (or P-Tau-181) protein solutions 


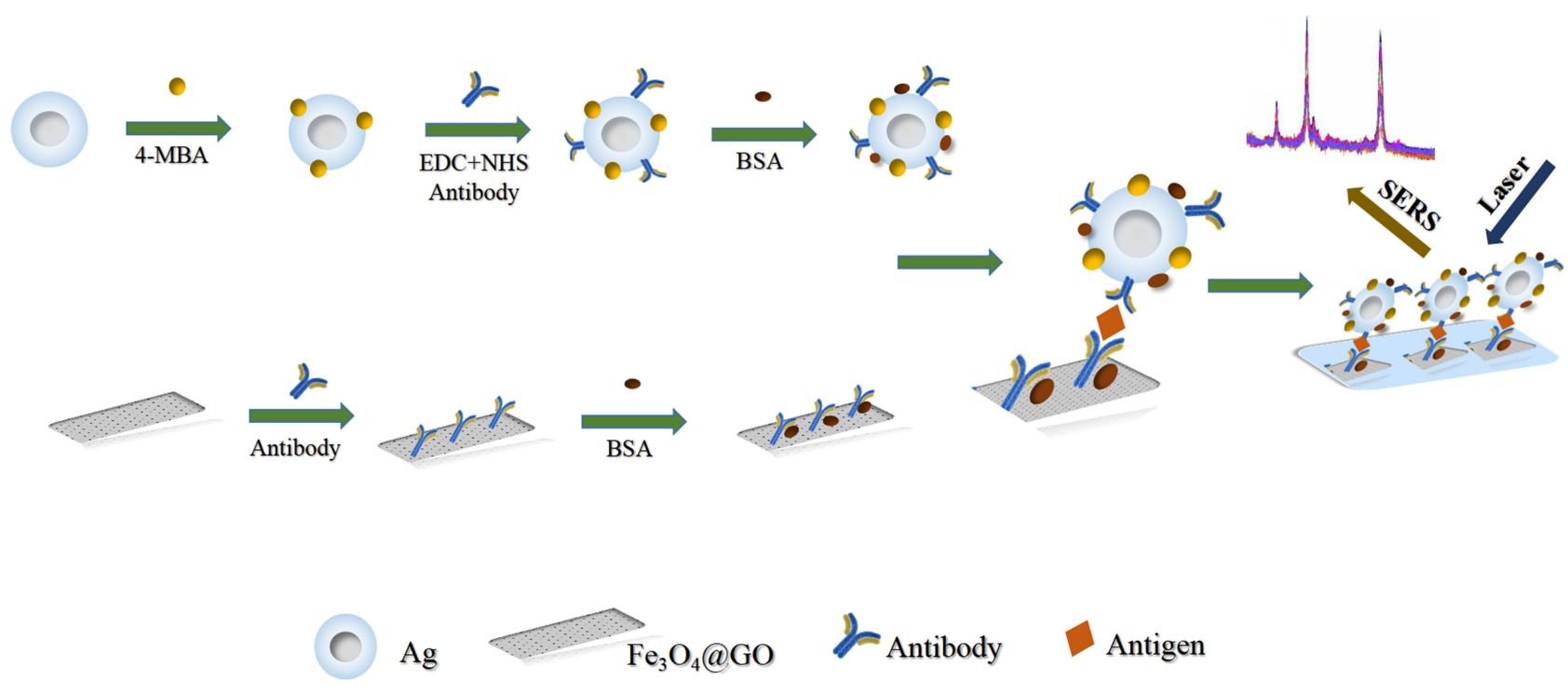

Scheme I Schematic illustration of the preparation and application of SERS-based immunoassay for detection of Alzheimer's disease biomarkers.

with different concentrations (or diluted serum) were added into the tube. After being incubated for $3 \mathrm{~h}$ at room temperature, the mixture was washed with PBS by magnetic separation, which aimed to remove the unbound antigen. After that, $200 \mu \mathrm{L}$ of the as-prepared probe was dropped into the above acquisition and incubated for $2 \mathrm{~h}$ at room temperature. After magnetic separation and wash twice with PBS, the precipitate was dispersed in $100 \mu \mathrm{L}$ deionized water for SERS detection.

\section{Statistics}

The protein content differences of A $\beta 1-42$ and P-Tau-181 were analyzed by the Student's $t$-test. All statistical analyses were performed using the SPSS 20.0 software. $P<0.05$ for the difference was considered to be statistically significant.

\section{Results}

\section{Optimization of the Immunoassay Optimization of Probes}

The synthetic method of Au, Ag, and Au@Ag nano-probes was as described above. TEM images of these probes were shown in Fig. S1. The mono-dispersed Au and Au-Ag nanoparticles can be found in Figure S1A and S1C. Electron microscope energy spectrum analysis was carried out for the further characterization Au@Ag (Figure S1D). Different from Au and $\mathrm{Au}-\mathrm{Ag}$ nanoparticles, a coating layer on the surface of $\mathrm{Ag}$ nanoparticles can be observed in Figure S1B. Obviously, tannin or tannin-based compounds were formed on the surface of Ag nanoparticles, which can benefit the stability and selectivity of Ag nanoparticles and enhance the sensitivity and accuracy of the SERS results.

Synthesis parameters are important for the formation of tannin-coated Ag nanoparticles. Figure S2A-E represented the TEM images of nano-silver probe which were synthesized with different amounts of reaction agents. It can be found that $1.2 \mathrm{~mL} \mathrm{H} \mathrm{H}_{2}, 1.2 \mathrm{~mL} \mathrm{~N} \mathrm{~N}_{2} \mathrm{H}_{4} \cdot \mathrm{H}_{2} \mathrm{O}$, and 0.05 $\mathrm{g}$ tannic acid were the ideal parameters for the preparation of nano-silver probe. The absorption spectra of the above five Ag probes were shown in Figure S2F. It is clear that obvious peaks were observed near $400 \mathrm{~nm}$, which is the characteristic peak of silver nanoparticles. And the peak was slightly shifted when tannin was coated on the surface of Ag.

The Raman enhancement effect of these probes (tannincapped Ag, Au, and $\mathrm{Au} @ \mathrm{Ag}$ ) was also investigated with the same protein concentration. It is clear that the tannin-capped Ag probe had the best Raman enhancement effect and a large discrimination to differ concentrations of antigen (Figure S3B). Furthermore, there was little change of the SERS intensity on $\mathrm{Ag}$ probe in 30 days, which proved the protection against oxidation of Ag nanoparticle by tannin coating layer (Figure S3D). Obviously, tannin-capped Ag probe is an ideal probe for the detection of protein in this work.

\section{Optimal Concentration of 4-MBA}

Tannin-capped silver probe was chosen for further SERS optimization. Different concentrations $(0.001 \mathrm{mM}, 0.01 \mathrm{mM}$, $0.1 \mathrm{mM}, 1 \mathrm{mM}$ ) of 4-MBA ethanol solution were added to the silver probe solution. The following step of 4-MBA labeled probe preparation was as described above. It can be seen that 
the Raman signals were gradually enhanced with increasing concentrations of 4-MBA in Figure 1A. The Raman intensities were relatively weaker when concentrations of 4-MBA are $0.001 \mathrm{mM}, 0.01 \mathrm{mM}, 0.1 \mathrm{mM}$. However, the Raman intensity became stronger when the concentrations of 4-MBA increased to $1 \mathrm{mM}$. Further increasing the concentration of 4-MBA, the Raman intensity enhanced little. Hence, $1 \mathrm{mM}$ is a good choice concentration for following SERS detection.

\section{Optimization of Sandwich Immunoassays}

In order to determine the optimal amounts of antibody and probe for the immunoassay, the experimental conditions were further optimized. Figure $1 \mathrm{~B}$ and $\mathrm{C}$ showed the Raman spectra of different amounts of antibodies and probes added to the SERS platform, respectively. It can be clearly observed that the Raman signal was gradually enhanced by increasing the amounts of antibody or probe from $2 \mu \mathrm{L}$ to $200 \mu \mathrm{L}$. The intensity of the Raman signal was significantly enhanced may be due to the antigenantibody binding. However, the Raman signal was not much different with the addition of $200 \mu \mathrm{L}, 400 \mu \mathrm{L}$ antibody or probe, which may be attributed to the saturated concentration of antibody or probe. Based on this, the optimal amount of antibody and probe in this work was adopted as $200 \mu \mathrm{L}$, respectively. Optimization of sandwich immunoassays was shown in Table S1.

\section{Specificity of the Immunoassay}

The specificity of the prepared immunoassay was verified by adding different antigens to the immune system. First, $100 \mathrm{pg} \mathrm{mL}^{-1} \mathrm{~A} \beta$-amyloid protein and $100 \mathrm{pg} \mathrm{mL}^{-1}$ Tau181 protein were added into the $\mathrm{A} \beta$-amyloid antibodyconjugated immune systems for detection, respectively. In addition, we further tested the specificity by adding $100 \mathrm{fg} \mathrm{mL}^{-1} \mathrm{~A} \beta$-amyloid protein and the mixture of 100 fg $\mathrm{mL}^{-1} \mathrm{~A} \beta$-amyloid protein and $100 \mathrm{pg} \mathrm{mL}^{-1}$ Tau-181
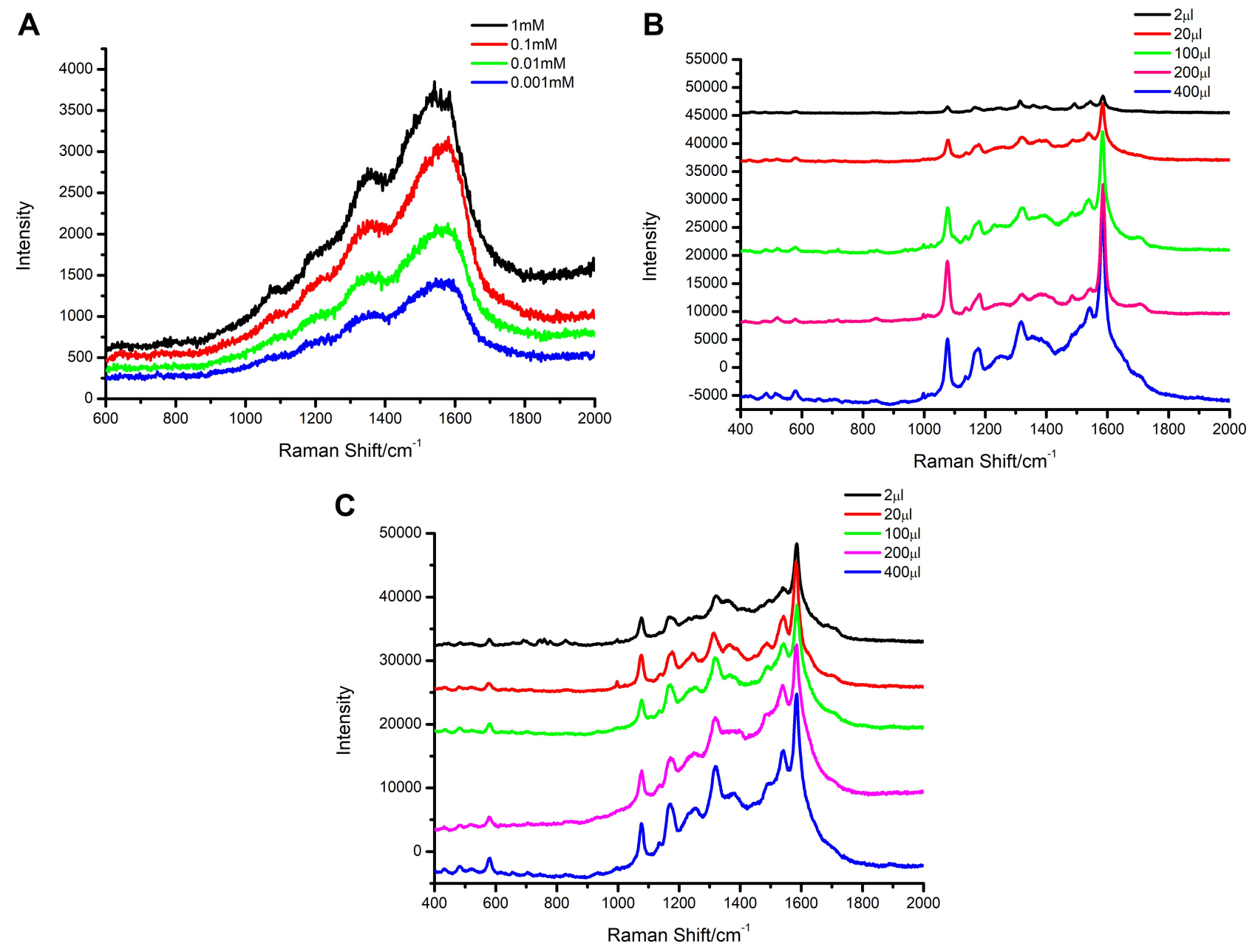

Figure I (A) Raman spectra of nano silver probes with different concentrations (0.00I mM, 0.01 mM, 0.I mM, I mM) of 4-MBA. (B) Raman spectra of different amount of specific antibodies ranging from $2 \mu \mathrm{L}$ to $400 \mu \mathrm{L}$. (C) Raman spectra of different amount of silver probe ranging from $2 \mu \mathrm{L}$ to $400 \mu \mathrm{L}$. 

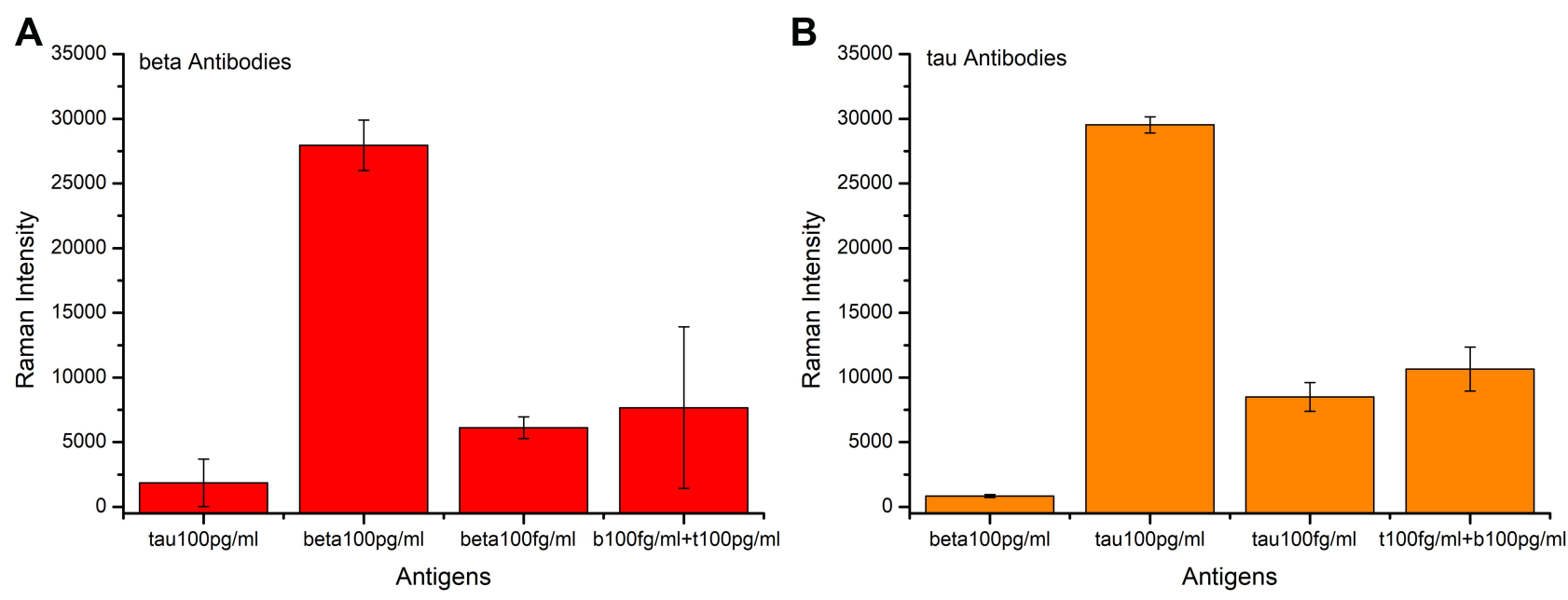

Figure 2 Specificity verification chart of proposed immunoassay. (A) A $\beta$-amyloid antibody-conjugated immunoassay. (B) Tau- $|8|$ antibody-conjugated immunoassay.

protein, respectively. The red bar graph plotted in Figure $2 \mathrm{~A}$ showed the measurement results. It can be seen from the figure that the $A \beta$-amyloid antibodyconjugated detection system had a strong Raman signal on the detection of $\beta$-protein, while the Raman intensity of other proteins was very weak. Furthermore, a much lower concentration of $\beta$-protein can be caught by our immunoassay even when there were amounts of other proteins in the buffer. These results illustrated that the proposed immunoassay can specifically and effectively detect the target protein. The same method was used to verify the specificity of Tau-181 antibody-conjugated immunoassay, and the results are plotted in Figure 2B.

\section{Characterization of $\mathrm{Ag}$ Probe}

The prepared silver probe was characterized further by X-ray diffraction (XRD). Figure 3A illustrates the XRD patterns of the prepared probes. All the diffraction peaks of the crystal planes (111), (200), (220), (311) could be indexed to $\mathrm{Ag}$ crystals, which convinced the as-prepared probe is $\mathrm{Ag}$.

\section{Characterization of the $\mathrm{Fe}_{3} \mathrm{O}_{4} @ \mathrm{GO}$ Substrate}

SEM image presented in Figure $3 \mathrm{~B}$ exhibited the basic morphological features of the $\mathrm{Fe}_{3} \mathrm{O}_{4} @ \mathrm{GO}$ substrate. It can be seen from the figure that the layered structure of the gray sheet was graphene oxide, and the small particles supported on it were $\mathrm{Fe}_{3} \mathrm{O}_{4}$. The good magnetic properties of $\mathrm{Fe}_{3} \mathrm{O}_{4} @ \mathrm{GO}$ dispersion are shown in Figure 3C.

\section{Calibration Curve and Limit Detection of Immunoassays}

In order to find the detection limit in buffer, standard protein solutions with different concentrations were measured by the suggested SERS-based immunoassay. Figure 4A and B showed the SERS spectra of the two protein standard protein solutions, respectively. From the spectra, two strong Raman peaks $\left(1585 \mathrm{~cm}^{-1}\right.$ and $\left.1076 \mathrm{~cm}^{-1}\right)$ of the labeled molecule (4-MBA) were observed. In addition, it was observed that the SERS intensity considerably declined with the dilution of antigens. And the SERS peaks of 4-MBA at $1585 \mathrm{~cm}^{-1}$ and $1076 \mathrm{~cm}^{-1}$ became very weak when the concentration of $A \beta$-amyloid or Tau-181 down to $10 \mathrm{fg} \mathrm{mL}^{-1}$ or $1 \mathrm{fg} \mathrm{mL}^{-1}$, respectively. Figure $4 \mathrm{C}$ and D showed the calibration curves at $1585 \mathrm{~cm}^{-1}$ peak of SERS intensity between the concentration of $\mathrm{A} \beta$-amyloid (with liner range from $10 \mathrm{fg} \mathrm{mL}^{-1}$ to $100 \mathrm{pg} \mathrm{mL}^{-1}$ ) or Tau181 (from $1 \mathrm{fg} \mathrm{mL}^{-1}$ to $100 \mathrm{pg} \mathrm{mL}^{-1}$ ). The linear regression equations for antigens were obtained, which were $Y=$ $5990 * X-4232$ (A $\beta$-amyloid) and $Y=5181 * X-1181$ (Tau$181)$, respectively. The correlation coefficient $\left(\mathrm{R}^{2}\right)$ was calculated to be 0.974 and 0.993 . As a result, the detection of limits could reach $1.62 \mathrm{fg} \mathrm{mL}^{-1}$ (A $\beta$-amyloid) and 5.74 fg $\mathrm{mL}^{-1}$ (Tau-181), respectively (Table S2). The above two obtained linear regression equations were then served as standard equations used for the calculation of antigens with unknown concentrations in the serum of patients.

\section{Application on Serum Samples}

To validate the potential diagnostic value of this immunoassay, two real serum samples were diluted $10-10^{3}$ times with PBS 
A

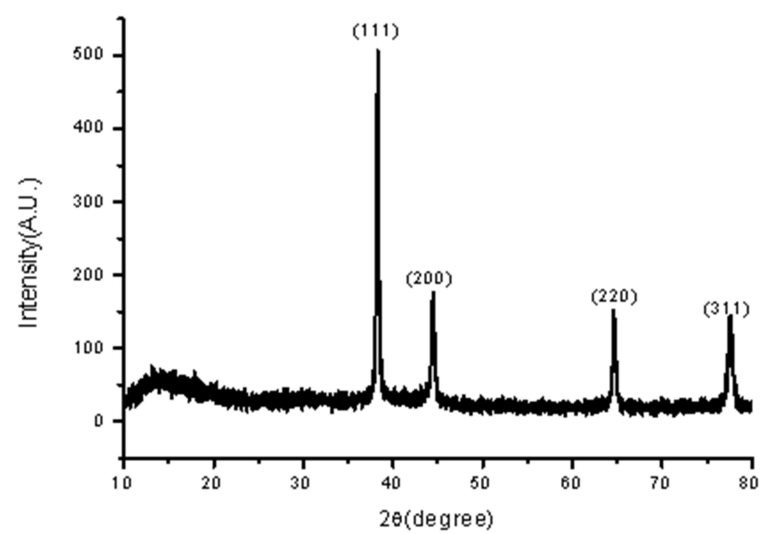

B

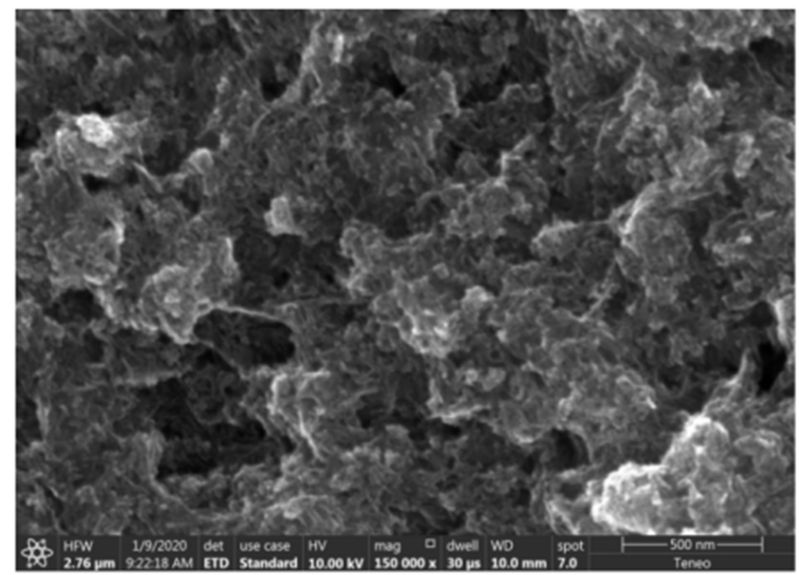

C

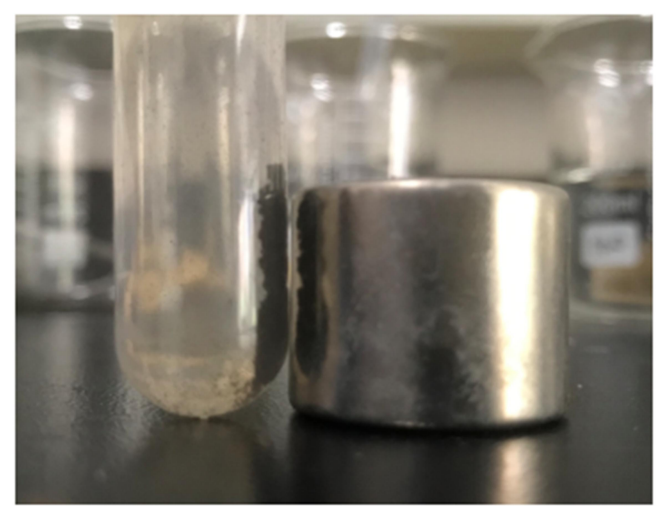

Figure 3 (A) XRD patterns of the as-prepared Ag probe. (B) SEM image of the $\mathrm{Fe}_{3} \mathrm{O}_{4} @ \mathrm{GO}$ substrates. (C) Good magnetic properties of Fe $\mathrm{O}_{4} @ \mathrm{GO}$ dispersion.

solution, separating into four serum dilutions with different concentrations of target proteins ranging from $\mathrm{C}_{0}$ to $1 \times 10^{-3}$ $\mathrm{C}_{0}$. As shown in Figure $5 \mathrm{~A}$ and $\mathrm{B}$, the obtained SERS spectrum marked a high-level capture of proteins (A $\beta$-amyloid or Tau181) and the SERS spectra of these different dilution ratios from patient's serum samples showed a distinct and gradually decreasing intensity. Then, the concentration of proteins was calculated via the above obtained standard linear regression equations. The results were as presented in Table S3, it can be seen that $90 \mathrm{fg} \mathrm{mL}^{-1}$ of $\mathrm{A} \beta 1-42$ and $9 \mathrm{fg} \mathrm{mL}^{-1} \mathrm{P}$-Tau-181 were successfully identified from serum samples.

Next, the proposed SERS method and ELISA were applied to the patient's serum samples. Pearson analysis was then applied to describe the correlation of detection results for the two methods above, $P<0.05$ was considered statistically significant. As illustrated in Table S4, the correlation coefficient of $A \beta 1-42$ detected by these two methods was 0.633 $(\mathrm{P}=0.000)$, which indicated an intensity correlation between the method of SERS and ELISA. Similar results were obtained on Tau protein, which showed a moderate correlation with the correlation coefficient was $0.565(\mathrm{P}=0.000)$.
Afterwards, a total of 63 serum samples were detected which consisted of 21 patients with AD, 20 non-AD dementia patients (13 patients with vascular dementia, 4 patients with Parkinson's Disease, and 3 cases of senile dementia) and 22 normal controls. After that, $t$-test was used to analyze the general data of the three groups. As shown in Table S5, there was no significant difference in age, $P>0.05$, which confirmed comparability between the three groups. After that, differences between groups were investigated by a twosample independent $t$-test. The results indicated that the proposed method was sensitive to detect proteins in serum samples. Histograms of $\mathrm{A} \beta 1-42$ and Tau-181 protein between groups are shown in Figure 6A. The concentration (mean with SD) of Aß1-42 (58.56 $\left.\pm 23.32 \mathrm{pg} \mathrm{mL}^{-1}, 95 \% \mathrm{CI}\right)$ in AD patients was lower than that of NADD patients $(96.96$ $\left.\pm 70.48 \mathrm{pg} \mathrm{mL}^{-1}, 95 \% \mathrm{CI}, p<0.05\right)$ and normal control (72.24 $\left.\pm 40.12 \mathrm{pg} \mathrm{mL}^{-1}, 95 \% \mathrm{CI}, p>0.05\right)$. While the concentration (mean with SD) of P-Tau-181 was found to be significantly higher in the case of $\mathrm{AD}\left(29.00 \pm 9.10 \mathrm{pg} \mathrm{mL}^{-1}, 95 \% \mathrm{CI}\right)$ than that of NADD $\left(24.30 \pm 14.22 \mathrm{pg} \mathrm{mL}^{-1}, 95 \% \mathrm{CI}, p<0.05\right)$ and normal control $\left(18.31 \pm 5.53 \mathrm{pg} \mathrm{mL}^{-1}, 95 \% \mathrm{CI}, p<0.01\right)$. 

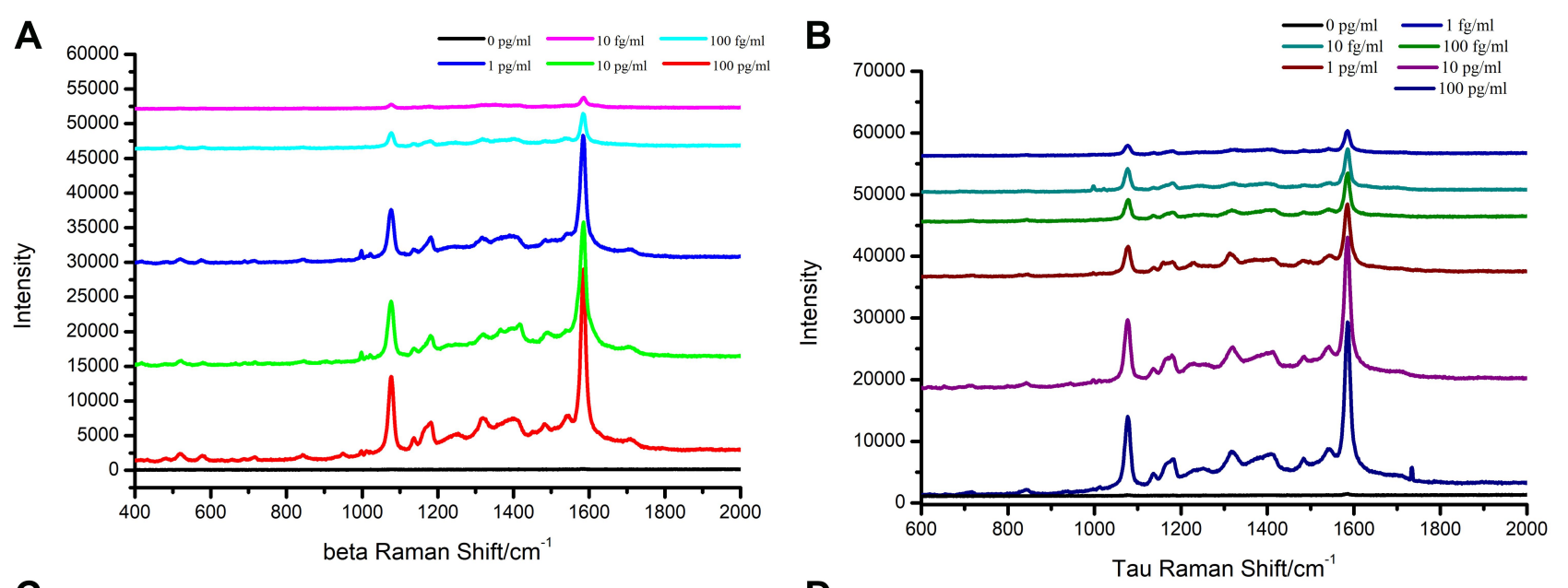

C

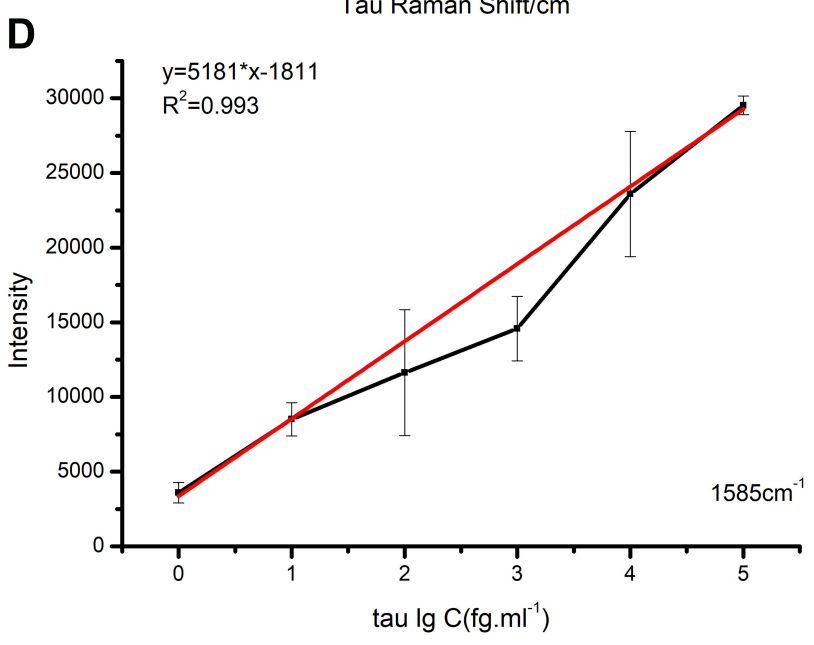

Figure 4 SERS spectra of 4-MBA for (A) A -amyloid and (B) Tau-18I with different concentration and the calibration curves of the peak intensity at $1585 \mathrm{~cm}^{-1}$ changed with the Ig value of protein concentration of (C) $A \beta$-amyloid and (D) Tau-18I.
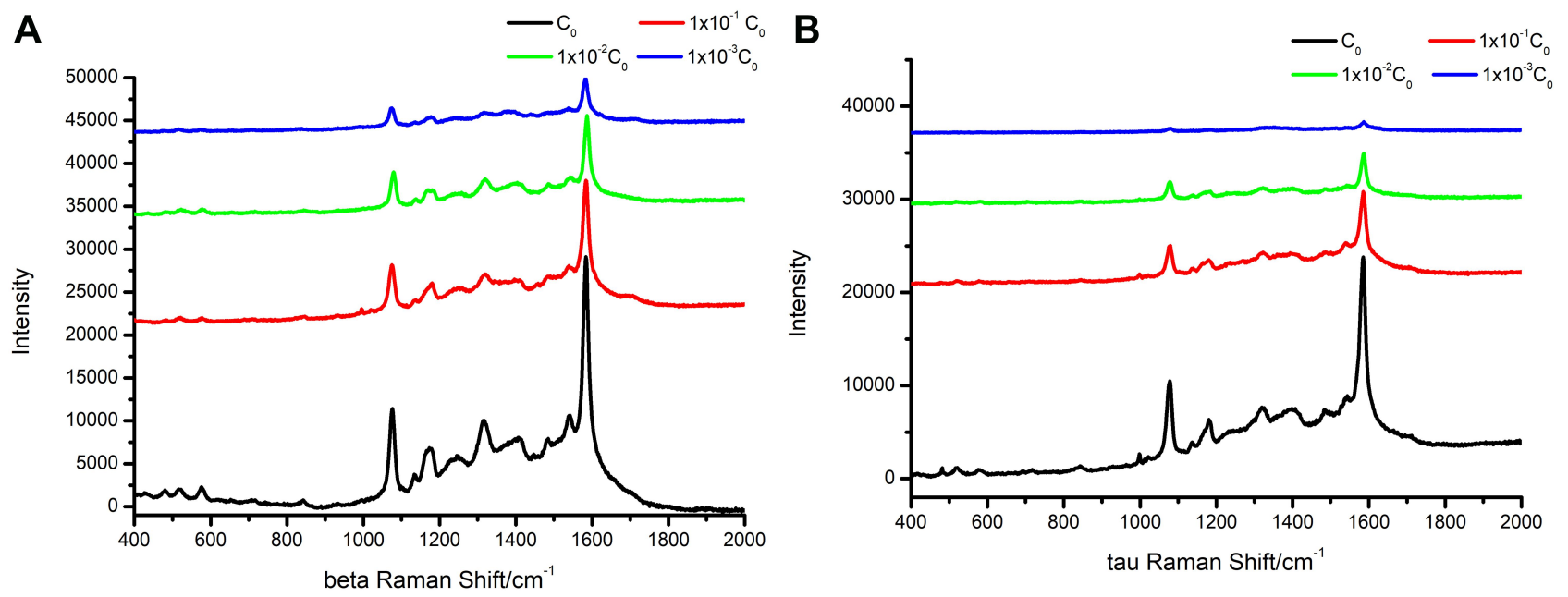

Figure 5 The SERS spectra of different dilution ratios from patient serum samples. (A) A $\beta$-amyloid. (B) Tau-I8I. 

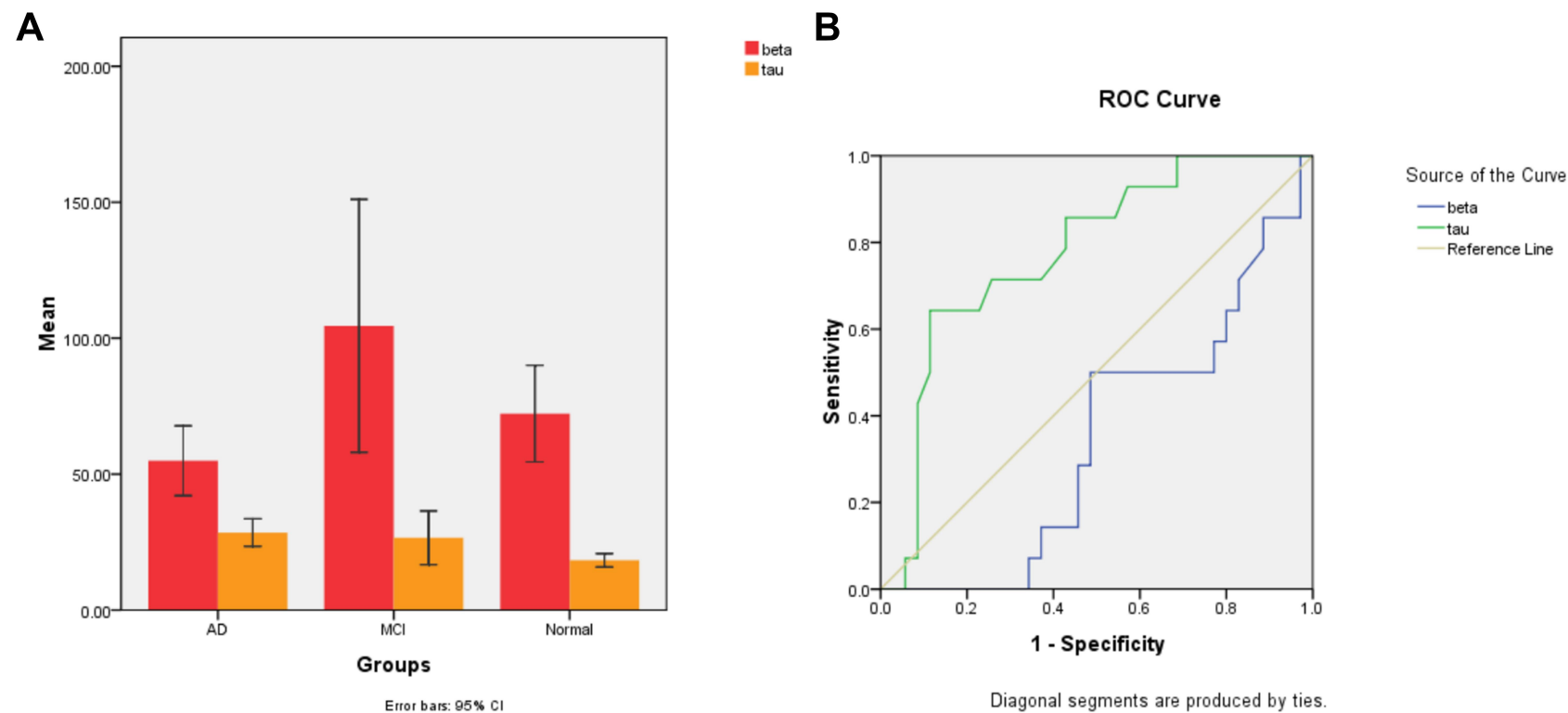

Figure 6 (A) Histogram of A $\beta$-amyloid (red) and Tau-18I (yellow) protein comparison between groups. (B) ROC curves of A $\beta$ I-42 (green) and Tau-I8I (blue) to discriminate between $A D$ and NADD patients.

The diagnostic values to discriminate AD from NADD of the biomarkers are presented in Figure 6B. As can be seen from Figure 6B, ROC analysis revealed that the area under curve (AUC) for $\mathrm{A} \beta 1-42$ was 0.383, while for Tau181 was 0.770 . Therefore, P-Tau-181 can be served as a sensitive serum biomarker for early diagnosis and differential diagnosis of AD.

\section{Discussion}

The pathogenesis of Alzheimer's disease has been investigated by many scholars, $\mathrm{A} \beta 1-42$ and P-Tau- 181 are considered to be two main causes. Therefore, the diagnostic value of A $\beta 1-42$ and P-Tau-181 has gradually increased. Cerebrospinal fluid is often used for detection, ${ }^{31,32}$ but it has the disadvantages of difficult sample acquisition and great harm to patients. Since then, serum or plasma has been proved to be a new medium for the detection of Alzheimer's disease biomarkers. Although the problem of sample collection is solved, the detection method has the drawbacks of low sensitivity and specificity. Since a new method with high sensitivity and specificity is in urgent.

Fortunately, SERS is proved to be an ultra-sensitive detection method that has been widely applied for detection. ${ }^{16,33}$ Table S6 shows related immunoassay methods for the detection of biomarkers in AD disease. Demeritte et al have developed a hybrid graphene oxidebased multifunctional nanoplatform with a magnetic core- plasma shell attachment. ${ }^{26}$ The platform allows for highly selective isolation of $\beta$-amyloid and tau protein from whole blood samples. Direct capture has been applied on the antibody-conjugated nanoplatforms, which can be used for the identification of $\mathrm{AD}$ biomarkers even at a level of $100 \mathrm{fg} \mathrm{mL} \mathrm{m}^{-1}$. Direct capture may induce more non-specific adsorption, and the reaction between antigen and antibody could gradually weaken with time. In this study, we designed a novel SERS-based method for the detection of AD biomarkers. The stability of Ag nanoparticles was significantly enhanced by tannic acid encapsulation, which enabled strong Raman signal intensity within 30 days. In addition, sandwich immunoassay could contribute to more specific target capture.

A dual-functional SERS platform has been developed for adiponectin and leptin detection by Wang et al. ${ }^{34} \mathrm{Fe}_{3} \mathrm{O}_{4}$ @ $\mathrm{SiO}_{2} @ \mathrm{Ag}$ core-shell particles have the dual functions of detecting target proteins and facilitating magnetic separation. The detection limits of adiponectin and leptin could lead to $25 \mathrm{pg} \mathrm{mL}^{-1}$ and $20 \mathrm{pg} \mathrm{mL}^{-1}$, respectively. In our design, we screened Ag as an SERS probe with the best Raman signal enhancement. After capturing the antigen, the distance between immune-silver probes and GO substrates will be smaller, which could further enhance the Raman scattering intensity of 4-MBA, thus achieving the ultra-sensitive quantitative detection of proteins with detection limits of 1.62 fg $\mathrm{mL}^{-1}$ and $5.74 \mathrm{fg} \mathrm{mL}^{-1}$. Several studies ${ }^{35,36}$ indicated that compared with healthy people, $\mathrm{AD}$ patients have 
decreased $A \beta 1-42$, and increased P-tau-181 in cerebrospinal fluid. However, patients with non-AD dementia have higher levels of A $\beta 1-42$, while P-tau-181 were slightly higher in patients with $\mathrm{AD}$. The area under the ROC curve is greater than 0.6. The results examined in this paper were basically consistent with previous findings. ROC analysis revealed that P-tau-181 performs better in distinguishing AD from nonAD dementia with an AUC of 0.770 , which indicates that A $\beta 1-42$ and P-tau-181 can serve as sensitive biomarkers for differential diagnosis of $\mathrm{AD}$ and non-AD dementia. However, the diagnostic value of $A \beta 1-42$ was weak which may be due to the insufficient sample size.

\section{Conclusion}

In summary, we proposed a novel SERS-based immunoassay with specific antibodies attaching to $\mathrm{Fe}_{3} \mathrm{O}_{4} @$ GOs and MBAlabeled silver probes. Target proteins were captured by the sandwich assay. The obtained SERS spectrum of 4-MBA represented the capture of target proteins. Such a method was first applied to protein standards and was then verified and applied on serum samples. Its detection limit in serum samples could reach the order of femtograms. Overall, the proposed SERS-based immunoassay is a specific and sensitive method that could provide new possibilities for the detection of clinical biomarkers. P-tau-181 could serve as a potential biomarker for early diagnosis of Alzheimer's disease and differential diagnosis of $\mathrm{AD}$ and NADD.

\section{Funding}

We thank Affiliated Hospital of Xuzhou Medical University for providing serum samples and all the medical record diagnostic information. This work was supported by the grant from the National Natural Science of China(No.81702061), the Jiangsu Provincial Commission of Health and Family Planning (No. Q2017010) and the Jiangsu Provincial Medical Youth Talent (No. QNRC2016781).

\section{Disclosure}

The authors report no conflicts of interest in this work.

\section{References}

1. Citron M. Alzheimer's disease: treatments in discovery and development. Nat Neurosci. 2002;5:1055-1057. doi:10.1038/nn940

2. Alzheimer's Association. 2016 Alzheimer's disease facts and figures. Alzheimers Dement. 2016;12(4):459-509.

3. Reitz C, Mayeux R. Alzheimer disease: epidemiology, diagnostic criteria, risk factors and biomarkers. Biochem Pharmacol. 2014;88 (4):640-651. doi:10.1016/j.bcp.2013.12.024
4. Kukull WA, Bowen JD. Dementia epidemiology. Med Clin North Am. 2002;86(3):573-590. doi:10.1016/S0025-7125(02)00010-X

5. Cummings BJ, Cotman CW. Image analysis of beta-amyloid load in Alzheimer's disease and relation to dementia severity. Lancet. 1995;346(8989):1524-1528. doi:10.1016/S0140-6736(95)92053-6

6. Citron M, Teplow DB, Selkoe DJ. Generation of amyloid beta protein from its precursor is sequence specific. Neuron. 1995;14(3):661-670. doi:10.1016/0896-6273(95)90323-2

7. Zhang X, Liu S, Song X, et al. Robust and universal SERS sensing platform for multiplexed detection of Alzheimer's disease core biomarkers using PAapt-AuNPs conjugates. ACS Sens. 2019;4 (8):2140-2149. doi:10.1021/acssensors.9b00974

8. Kuperstein I, Broersen K, Benilova I, et al. Neurotoxicity of Alzheimer's disease $A \beta$ peptides is induced by small changes in the $\mathrm{A} \beta 42$ to $\mathrm{A} \beta 40$ ratio. EMBO J. 2010;29(19):3408-3420. doi:10.1038/ emboj.2010.211

9. Zengin A, Tamer U, Caykara T. A SERS-based sandwich assay for ultrasensitive and selective detection of Alzheimer's tau protein. Biomacromolecules. 2013;14(9):3001-3009. doi:10.1021/bm400968x

10. Ulanova M, Poljak A, Wen W, et al. Nanoparticles as contrast agents for the diagnosis of Alzheimer's disease: a systematic review. Nanomedicine (Lond). 2020;15(7):725-743. doi:10.2217/nnm-2019-0316

11. Xu K, Liang ZC, Ding X, et al. Nanomaterials in the prevention, diagnosis, and treatment of mycobacterium tuberculosis infections. Adv Healthc Mater. 2018;7(1):1700509. doi:10.1002/adhm.201700509

12. Englund H, Sehlin D, Johansson AS, et al. Sensitive ELISA detection of amyloid- $\beta$ protofibrils in biological samples. $J$ Neuro Chem. 2007;103:1471-4159.

13. Butler HJ, Ashton L, Bird B, et al. Using Raman spectroscopy to characterize biological materials. Nat Protoc. 2016;11(4):664-687. doi:10.1038/nprot.2016.036

14. Song C, Yang B, Zhu Y, Yang Y, Wang L. Ultrasensitive sliver nanorods array SERS sensor for mercury ions. Biosens Bioelectron. 2017;87:59-65. doi:10.1016/j.bios.2016.07.097

15. Zhou W, Yin BC, Ye BC. Highly sensitive surface-enhanced Raman scattering detection of hexavalent chromium based on hollow sea urchin-like $\mathrm{TiO}_{2} @ \mathrm{Ag}$ nanoparticle substrate. Biosens Bioelectron. 2017;87:187-194. doi:10.1016/j.bios.2016.08.036

16. Yang K, Hu Y, Dong N, Zhu G, Zhu T, Jiang N. A novel SERS-based magnetic aptasensor for prostate specific antigen assay with high sensitivity. Biosens Bioelectron. 2017;94:286-291. doi:10.1016/j. bios.2017.02.048

17. Fan M, Andrade GFS, Brolo AG. A review on recent advances in the applications of surface-enhanced Raman scattering in analytical chemistry. Anal Chim Acta. 2020;1097:1-29.

18. You YH, Lin YF, Nirosha B, Chang HT, Huang YF. Polydopaminecoated gold nanostar for combined antitumor and antiangiogenic therapy in multidrug-resistant breast cancer. Nanotheranostics. 2019;3(3):266-283. doi:10.7150/ntno.36842

19. Li M, Wu J, Ma M, et al. Alkyne- and nitrile-anchored gold nanoparticles for multiplex SERS imaging of biomarkers in cancer cells and tissues. Nanotheranostics. 2019;3(1):113-119. doi:10.7150/ntno.30924

20. Weber F, Barrantes A, Tiainen H. Silicic acid-mediated formation of tannic acid nanocoatings. Langmuir. 2019;35(9):3327-3336. doi:10.1021/acs.langmuir.8b04208

21. Zoppi A, Trigari S, Giorgetti E, et al. Functionalized Au/Ag nanocages as a novel fluorescence and SERS dual probe for sensing. $J$ Colloid Interface Sci. 2013;407:89-94. doi:10.1016/j. jcis.2013.06.012

22. Zhou T, Fan M, You R, et al. Fabrication of $\mathrm{Fe}_{3} \mathrm{O}_{4} / \mathrm{Au} @ \mathrm{ATP} @ \mathrm{Ag}$ Nanorod sandwich structure for sensitive SERS quantitative detection of histamine. Anal Chim Acta. 2020;1104:199-206. doi:10.1016/j. aca.2020.01.017

23. Loh KP, Bao Q, Eda G, Chhowalla M. Graphene oxide as a chemically tunable platform for optical applications. Nat Chem. 2010;2(12):1015-1024. doi:10.1038/nchem.907 
24. PramaniK A, Jones S, Gao Y, et al. Multifunctional hybrid graphene oxide for circulating tumor cell isolation and analysis. Adv Drug Deliv Rev. 2018;125:21-35. doi:10.1016/j.addr.2018.01.004

25. Thangamuthu M, Hsieh KY, Kumar PV, Chen GY. Graphene- and graphene oxide-based nanocomposite platforms for electrochemical biosensing applications. Int $J$ Mol Sci. 2019;20(12):2975 doi:10.3390/ijms20122975

26. Demeritte T, Nellore BP, Kanchanapally R, et al. Hybrid graphene oxide based plasmonic-magnetic multifunctional nanoplatform for selective separation and label-free identification of Alzheimer's disease biomarkers. ACS Appl Mater Interfaces. 2015;7 (24):13693-13700. doi:10.1021/acsami.5b03619

27. Liu Y, Qi Y, Yin C, et al. Bio-transformation of graphene oxide in lung fluids significantly enhances its photothermal efficacy. Nanotheranostics. 2018;2(3):222-232. doi:10.7150/ntno.25719

28. Dong YL, Zhang HG, Rahman ZU, et al. Graphene oxide-Fe3O4 magnetic nanocomposites with peroxidase-like activity for colorimetric detection of glucose. Nanoscale. 2012;4(13):3969-3976. doi:10.1039/c2nr12109c

29. Liao W, Lin Q, Xu Y, Yang E, Duan Y. Preparation of Au@Ag core-shell nanoparticle decorated silicon nanowires for bacterial capture and sensing combined with laser induced breakdown spectroscopy and surface-enhanced Raman spectroscopy. Nanoscale. 2019;11(12):5346-5354. doi:10.1039/C9NR00019D

30. Yang Y, Yan Q, Liu Q, et al. An ultrasensitive sandwich-type electrochemical immunosensor based on the signal amplification strategy of echinoidea-shaped $\mathrm{Au} @ \mathrm{Ag}-\mathrm{Cu}_{2} \mathrm{O}$ nanoparticles for prostate specific antigen detection. Biosens Bioelectron. 2018;99:450-457. doi:10.1016/j.bios.2017.08.018
31. Mo JA, Lim JH, Sul AR, Lee M, Youn YC, Kim HJ. Cerebrospinal fluid $\beta$-amyloid1-42 levels in the differential diagnosis of Alzheimer's disease-systematic review and meta-analysis. PLoS One. 2015;10(2):e0116802. doi:10.1371/journal.pone.0116802

32. Chen Z, Liu C, Zhang J, Relkin N, Xing Y, Li Y. Cerebrospinal fluid $\mathrm{A} \beta 42$, t-tau, and p-tau levels in the differential diagnosis of idiopathic normal-pressure hydrocephalus: a systematic review and meta-analysis. Fluids Barriers CNS. 2017;14(1):13. doi:10.1186/s12987-017-0062-5

33. Li X, Yang T, Li CS, et al. Surface Enhanced Raman Spectroscopy (SERS) for the multiplex detection of Braf, Kras, and Pik3ca Mutations in plasma of colorectal cancer patients. Theranostics. 2018;8(6):1678-1689. doi:10.7150/thno.22502

34. Wang X, Wang M, Jiang T, et al. Dual-functional $\mathrm{Fe}_{3} \mathrm{O}_{4} @ \mathrm{SiO}_{2} @ \mathrm{Ag}$ triple core-shell microparticles as an effective SERS platform for adipokines detection. Colloids Surf A. 2017;535:24-33. doi:10.1016/j.colsurfa.2017.09.025

35. Struyfs H, Niemantsverdriet E, Goossens J, et al. Cerebrospinal fluid P-Tau181P: biomarker for improved differential dementia diagnosis. Front Neurol. 2015;6:138. doi:10.3389/fneur.2015.00138

36. Somers C, Lewczuk P, Sieben A, et al. Validation of the Erlangen Score Algorithm for differential dementia diagnosis in autopsy-confirmed subjects. J Alzheimers Dis. 2019;68 (3):1151-1159. doi:10.3233/JAD-180563
International Journal of Nanomedicine

\section{Publish your work in this journal}

The International Journal of Nanomedicine is an international, peerreviewed journal focusing on the application of nanotechnology in diagnostics, therapeutics, and drug delivery systems throughout the biomedical field. This journal is indexed on PubMed Central, MedLine, CAS, SciSearch ${ }^{\circledR}$, Current Contents ${ }^{\circledR} /$ Clinical Medicine,
Journal Citation Reports/Science Edition, EMBase, Scopus and the Elsevier Bibliographic databases. The manuscript management system is completely online and includes a very quick and fair peer-review system, which is all easy to use. Visit http://www.dovepress.com/ testimonials.php to read real quotes from published authors. 